\title{
Novel synthesis of coordination biopolymer precursor from oxidation of methyl cellulose by alkaline potassium
} permanganate

\author{
Hassan $\mathrm{RM}^{1 *}$ and Ibrahim $\mathrm{SM}^{2}$ \\ ${ }^{1}$ Chemistry Department, Faculty of Science, Assiut University, Assiut 71516 Egypt \\ ${ }^{2}$ Chemistry Department, Faculty of Science, New Valley University, El-Kharga 72511, New Valley, Egypt
}

\begin{abstract}
Purpose of the study: Synthesis of diketomethyl cellulose.

Materials and method: Diketomethyl cellulose was quantitatively prepared by the oxidation of methyl cellulose by potassium permanganate in alkaline medium at $\mathrm{pH} ` \mathrm{~s}>12$.

Results: The dike to-derivative was characterized by formation of 2,4-dinitrophenyl hydrazone and dioxime derivatives when reacting with dinitrophenyl haydrazine and hydroxyl amine, respectively, as well as by the FTIR spectral bands observed at 1760-1730 $\mathrm{cm}^{-1}$ that characterize to the carbonyl group of $\alpha$-diketones.

Conclusion: This oxidation product can be used as a dietary fiber and a functional fiber when added to food. In addition, it found that the product has a high affinity for chelation with most of divalent and polyvalent metal ions forming stable coordination biopolymer complexes of methyl cellulose. The product is characterized by its non-toxicity, low cost and high performance. Diketomethyl cellulose can be used effectively for removal of poisonous heavy metal ions such as $\mathrm{Sn}^{2+}, \mathrm{Cd}^{2+}, \mathrm{Hg}^{2+}$ and $\mathrm{Pb}^{2+}, \mathrm{Ca}^{2+}$ along with other divalent and polyvalent metal ions which are contaminated in wastewater and environment.
\end{abstract}

\section{Introduction}

Cellulose is the major component of cell walls in plant. It is considered as a dietary fiber as well as a functional fiber when added to food [1]. Methyl cellulose (MC) is a cellulose ether derivative. It is a water-soluble due to the presence of hydroxyl moieties at C-2 and $\mathrm{C}-3$ positions which prevent extensive hydrogen bonding. It is a hydrophilic macromolecule unless the temperature exceeds that of the lower critical temperature of solution (LCST) of the approximate range $40-70{ }^{\circ} \mathrm{C}$ [2]. Therefore, this natural polymer is expected to have advantageous as a dietary fiber in food industry.

The kinetics and mechanisms of oxidation of polysaccharides such as alginates [3], pectates [4], methyl cellulose [5,6], carboxymethyl cellulose [7], carrageenan [8,9] and chondroitin-4-sulfate [10] by alkaline permanganate have been investigated in more details as reported elsewhere. However, the synthesis of the keto-derivatives for the oxidation of products of the studied polysaccharides was reported elsewhere $[11,12]$, it seems that no mention on the synthesis of the methyl cellulose keto-derivatives.

Moreover, it was reported that the high tendency of alginate polysaccharide to form coordination biopolymers with polyvalent metal cations was attributed to the presence of both carboxylate and hydroxyl groups within the monomers [13]. This means that the presence of such groups in particularly the carboxylate groups within the monomers is essential for formation of such coordination biopolymer complexes. Despite the absence of carboxylate groups within the skeleton of the synthesized diketo-methyl cellulose, preliminary experiments indicated its high tendency to form stable coordination biopolymer complexes with di- and polyvalent metal ions.

The above aspects in addition to our interest in the kinetic studies of oxidation of macromolecules by this oxidant [3-10], we have prompted to undertake the present investigation with the aims to synthesize a novel coordination biopolymer precursor as a chelating agent with high affinity for chelating di- and polyvalent metal ions.

\section{Experimental}

\section{Materials}

All materials used were of analytical grade. Doubly distilled water was used in all preparations.

Methyl cellulose (MP Biomedicals, LLC) (MC) was used without further purification. The viscosity of $2 \%$ solution was found to be 4000 centipoise at $20^{\circ} \mathrm{C}$. The molecular weight is about 50.000 Dalton. The preparation of the stock solution of MC was the same as described elsewhere [14]. This procedure was performed by the addition of methyl cellulose powder regent to bidistilled water whilst rapidly stirring the solution to avoid the formation of lumps which swell with

*Correspondence to: Hassan RM, Chemistry Department, Faculty of Science, Assiut University, Assiut 71516 Egypt, Tel: 01116770589; E-mail: rmhassan2002@yahoo.com

Key words: methyl cellulose, dietary fiber, chelating agent, permanganate

Received: June 03, 2018; Accepted: July 01, 2019; Published: July 05, 2019 
difficult. A stock solution of permanganate was prepared, stored and standardized as described elsewhere $[15,16]$. All other reagents were prepared by dissolving the requisite amounts of the sample in doubly distilled water.

\section{Preparation of diketomethy cellulose (DKMC)}

Methyl cellulose powder $(5 \mathrm{~g})$ was dissolved in $350 \mathrm{~cm}^{3}$ of deionized water whose $\mathrm{pH}$ was previously adjusted to $\mathrm{pH} \geq 12$ using sodium hydroxide. This process was performed by stepwise addition of the powder MC to the solution while stirring rapidly and continuously to avoid the formation of aggregates. A $150 \mathrm{~cm}^{3}$ solution containing 3.87 $\mathrm{g}$ of potassium permanganate and $4.07 \mathrm{~g}$ of sodium fluoride was then added stepwise over $2 \mathrm{~h}$ to the MC solution. The reaction mixture was stirred for $48 \mathrm{~h}$ at room temperature, the formed $\mathrm{MnF}_{4}$ was filtered off, and the solution was concentrated to one-fifth of the original solution using a rotary evaporator. A portion of this concentrated solution was acidified using dilute acetic acid to a $\mathrm{pH}$ of ca. 5-6. The resultant solution dried under vacuum, and then subjected to elemental analysis and IR spectroscopy.

The diketo-derivative was characterized by formation of 2,4-dinitrophenyl hydrazone and dioxime derivatives when reacting with dinitrophenyl haydrazine and hydroxyl amine, respectively, as well as by the FTIR spectral bands observed at $1760-1730 \mathrm{~cm}^{-1}$ that characterize to the carbonyl group of $\alpha$-diketones.

\section{IR-spectra}

The IR-spectra were scanned on a Pyc Unicum Sp 3100 spectrophotometer using the $\mathrm{KBr}$ disc technique $\left(4000-200 \mathrm{~cm}^{-1}\right)$. ANAL: Diketomethyl cellulose (DKMC) $\mathrm{C}_{7} \mathrm{H}_{8} \mathrm{O}_{5}$ (172): Calcd (found): C, 48.84 (48.58); H, 4.65 (4.36). IR: 3473 (OH group); 1652-1634 (broad) (C=O of -diketone); 1634 ( $\gamma$ as OCO); 1417 ( $\gamma$ s OCO) and 1258 $\mathrm{cm}^{-1}(\mathrm{C}-\mathrm{O}-\mathrm{C}$ of $\mathrm{MC})$ [17].

\section{2, 4-Dinitrophenyl hydrazone derivative}

ANAL: $\mathrm{C}_{19} \mathrm{H}_{16} \mathrm{O}_{11} \mathrm{~N}_{8}$ (532): Cald (found): C, 42.86 (42.66); $\mathrm{H}, 3.01$ (3.0); N, 21.05 (21.1). IR: 3390 (OH group); 3310 ( $\mathrm{NH}$ of hydrazone); 1680 ( $\mathrm{C}=\mathrm{N}$ of hydrazone); 1200 (C-O-C of MC).

\section{Dioxime derivative}

ANAL: $\mathrm{C}_{7} \mathrm{H}_{10} \mathrm{O}_{5} \mathrm{~N}$ (188): Cald (found): C, 44.68 (44.69); $\mathrm{H}, 5.32$ (5.33); $\mathrm{N}, 7.45$ (7.42). IR: $3300(\mathrm{OH}$ of $\mathrm{COOH}$ and oxime); $1670(\mathrm{C}=\mathrm{N})$; $1595(\mathrm{C}=\mathrm{O}$ of $\mathrm{COOH}) ; 1225$ (C-O-C of $\mathrm{MC}$ ).

The diketo-derivative was also identified by elemental analysis and IR spectral data as described elsewhere $[18,19]$.

\section{Results and discussion}

\section{Stoichiometry}

Under our experimental conditions in the presence of initial $\left[\mathrm{MnO}_{4}^{-}\right] /[\mathrm{MC}]$ in $\geq 2.0$ molar ratio, the stoichiometry of oxidation conforms the following stoichiometric equation,

$2\left(\mathrm{C}_{7} \mathrm{H}_{12} \mathrm{O}_{5}\right)_{\mathrm{n}}+4 \mathrm{MnO}_{4}^{-}=2\left(\mathrm{C}_{7} \mathrm{H}_{8} \mathrm{O}_{5}\right)_{\mathrm{n}}+4 \mathrm{MnO}_{2}+4 \mathrm{OH}^{-}+2 \mathrm{H}_{2} \mathrm{O}+\mathrm{O}_{2}$

where $\mathrm{C}_{7} \mathrm{H}_{12} \mathrm{O}_{5}$ and $\mathrm{C}_{7} \mathrm{H}_{8} \mathrm{NO}_{5}$ represent the $\mathrm{MC}$ and its corresponding diketo-derivative, respectively. The oxidation product was found to be the same in either the presence or absence of nitrogen atmosphere indicating that the oxidation of the formed aldehyde occurs by permanganate ion oxidant rather than by the dissolved oxygen. The oxidation product was identified by the spectral data and elemental analysis [18]. The diketo-derivative was characterized by the formation of 2,4-dinitrophenyl hydrazone and dioxime derivatives as well as by the FTIR spectral bands observed at $1760-1730 \mathrm{~cm}^{-1}$ that characterize to the carbonyl group of $\alpha$-diketones [17] as shown in Figure 1.

On the other hand, when the molar ration between $\left[\mathrm{MnO}_{4}^{-}\right] /[\mathrm{MC}]$ is 1.0, monoketo-methyl cellulose is formed. Hence, the stoichiometry can be expressed by the following equation:

$$
2\left(\mathrm{C}_{7} \mathrm{H}_{12} \mathrm{O}_{5}\right)_{\mathrm{n}}+2 \mathrm{MnO}_{4}^{-}=2\left(\mathrm{C}_{7} \mathrm{H}_{10} \mathrm{O}_{5}\right)_{\mathrm{n}}+2 \mathrm{MnO}_{2}+2 \mathrm{OH}^{-}+\mathrm{H}_{2} \mathrm{O}+1 / 2 \mathrm{O}_{2}
$$

\section{Kinetics and mechanism}

The kinetics and mechanism for oxidation of MC substrate by alkaline [5,6] and acidic [20] permanganate have been discussed in more details earlier. In case of oxidation of MC by alkaline permanganate $[5,6]$, it was found that the oxidation process was proceeding through two distinct separate stages. The naked-eye observations indicated the change in color of the solution mixture from purple (Mn (VII)) to blue $(\mathrm{Mn}(\mathrm{V}))$ to green $(\mathrm{Mn}(\mathrm{VI}))$ to yellow (Mn (IV)). The first stage was relatively fast with formation of 1:1 intermediate transient coordination biopolymer complexes involving blue hypomamanganate $(\mathrm{V})$ and/ or green manganate (VI) transient species. This stage was followed by slow decomposition of these intermediates to give rise to the final oxidation products as monoketo- or diketo -methyl cellulose precursor derivatives in the final slow stage depending on the initial concentration molar ratio of reactants. Inner-sphere type of the electron transfer mechanism without free-radical intervention was suggested. On the other hand in case of oxidation of MC by acidic permanganate, the oxidation process was found also to proceed via two distinct stage of sigmoidal S-shape nature for pseudo first-order plots. The first stage was found to be relatively slow via formation of 1:2 intermediate complexes prior to the rate-determining step. It corresponds to the formation of substrate radical and $\mathrm{Mn}^{3+}$ and/or $\mathrm{Mn}^{4+}$ transient species as initial oxidation products. This stage was followed by a fast reaction to give rise to keto-derivatives of methyl cellulose in the second fast stage. The mechanisms of oxidation of methyl cellulose by acidic [5,6] and alkaline [20] permanganate are illustrated in Figures 2 and 3, respectively.

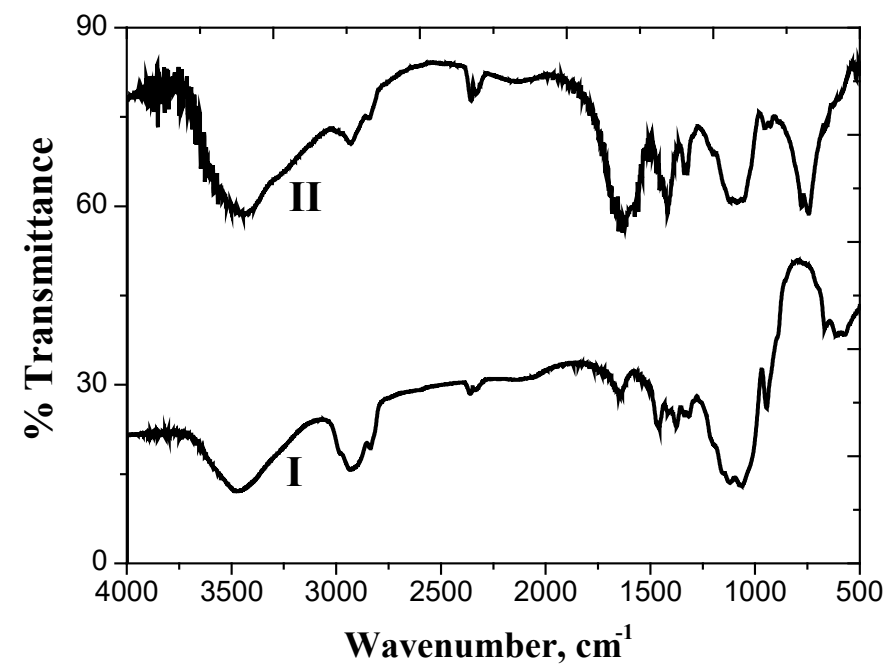

Figure 1. FTIR spectra of methyl cellulose (I) and its dike to derivative (II) 


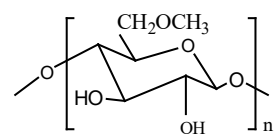

(Methyl cellulose)

$$
\mathrm{H}^{+} \| K
$$

$\mathrm{CH}_{2} \mathrm{OCH}_{3}$<smiles>CO[C@H]1O[C@H](O)[C@@H](O)[C@H](O)[C@H](C)[C@H]1O</smiles>

$\| \mathrm{MnO}_{4}^{-}$

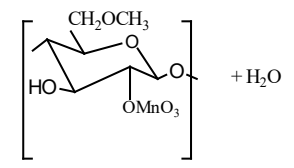

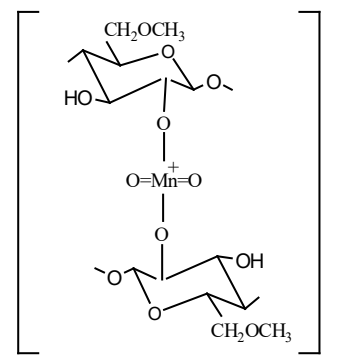

$+\mathrm{SH} \mid-\mathrm{H}_{2} \mathrm{O}$

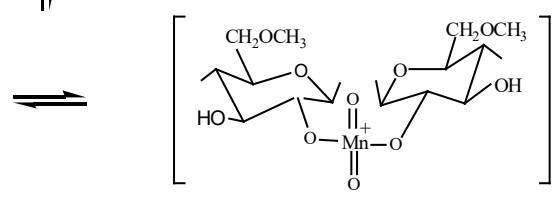

(Intra)<smiles>CC(C)(C)O</smiles>

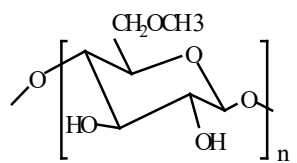

(Methyl cellulose )

$\mathrm{H}^{+} \|_{K}$<smiles>COC1OC(O)C(C)C(O)C1O</smiles>

$\| \mathrm{Mn}^{\mathrm{IV}}$

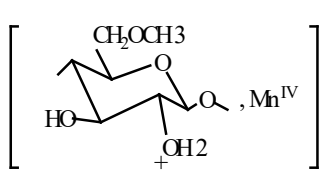

$-\mathrm{H} \| \mathrm{SH}^{+}$

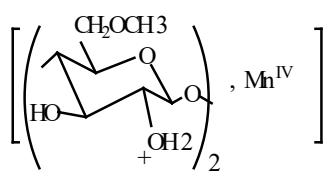

$2 \mathrm{H}_{3} \mathrm{O}^{+}+2(\underbrace{2}_{\mathrm{O}}$

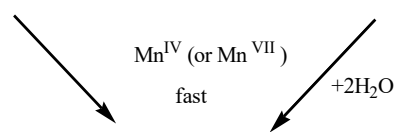

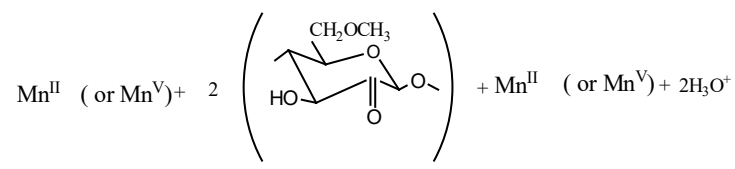

$2 \mathrm{Mn}(\mathrm{V})=\mathrm{Mn}(\mathrm{IV})+\mathrm{Mn}(\mathrm{VI})$

$\mathrm{Mn}(\mathrm{V})+\mathrm{Mn}(\mathrm{VII})=2 \mathrm{Mn}(\mathrm{VI})$

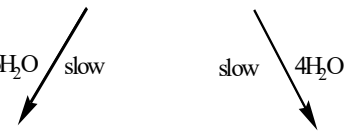

$\mathrm{Mn}(\mathrm{VI})=\mathrm{Mn}(\mathrm{IV})+\mathrm{Mn}(\mathrm{II})$

$\mathrm{Mn}(\mathrm{IV})+\mathrm{Mn}(\mathrm{II})=2 \mathrm{Mn}(\mathrm{III})$

\section{Slow stage}

Fast stage

Figure 2. Mechanism of oxidation of methyl cellulose by permanganate ion in aqueous perchlorate solutions for the slow and fast stages 


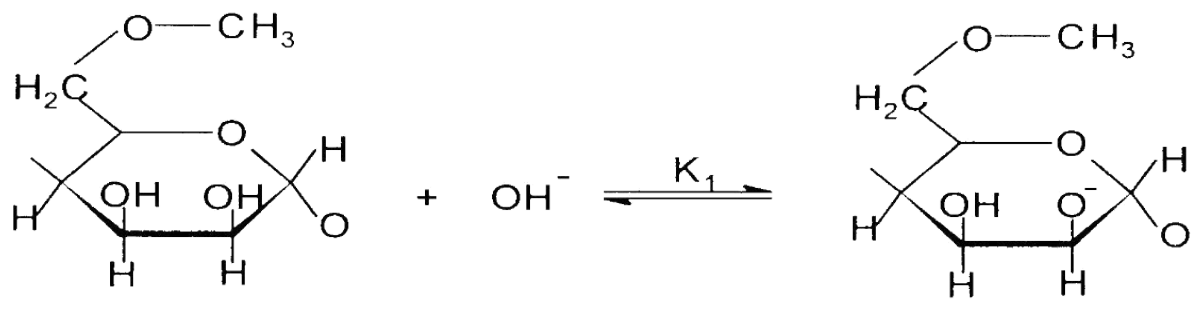

Methyl cellulose

alkoxide

[MC]
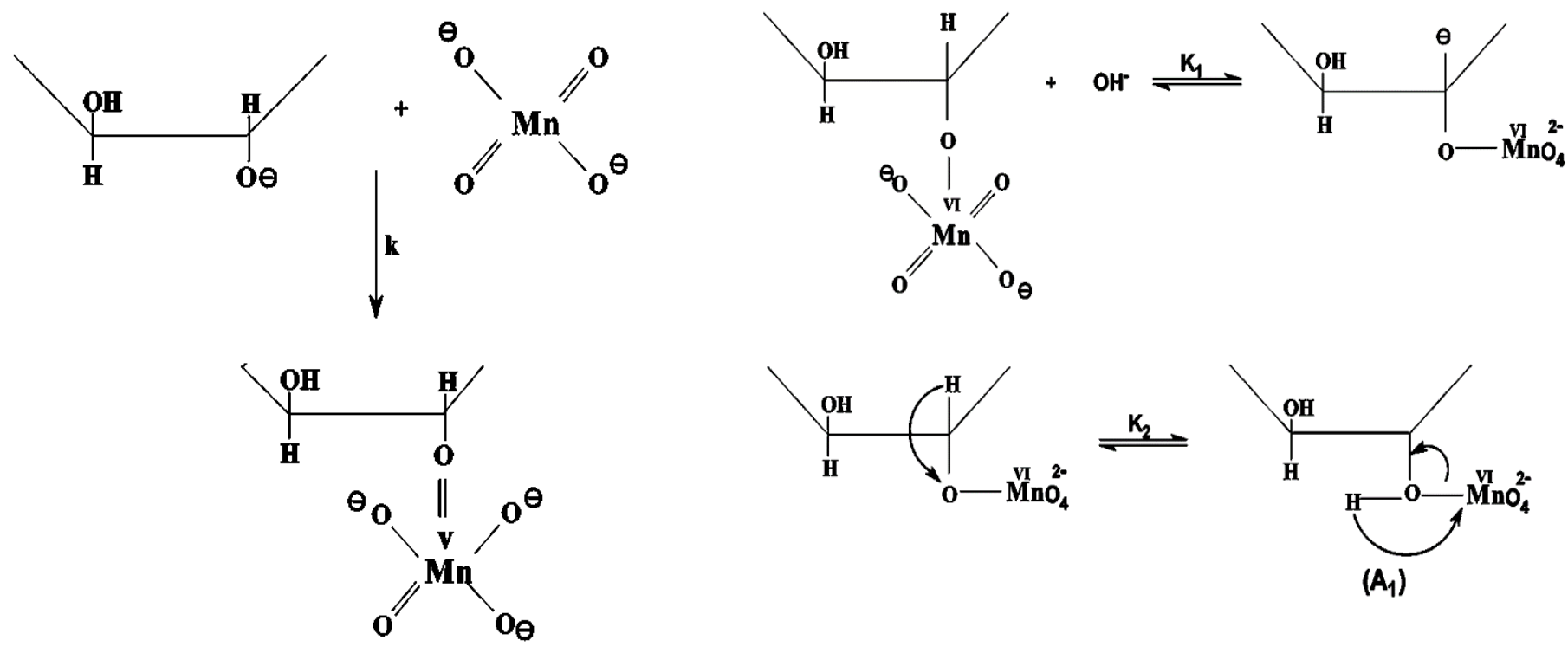

blue hypomanganate
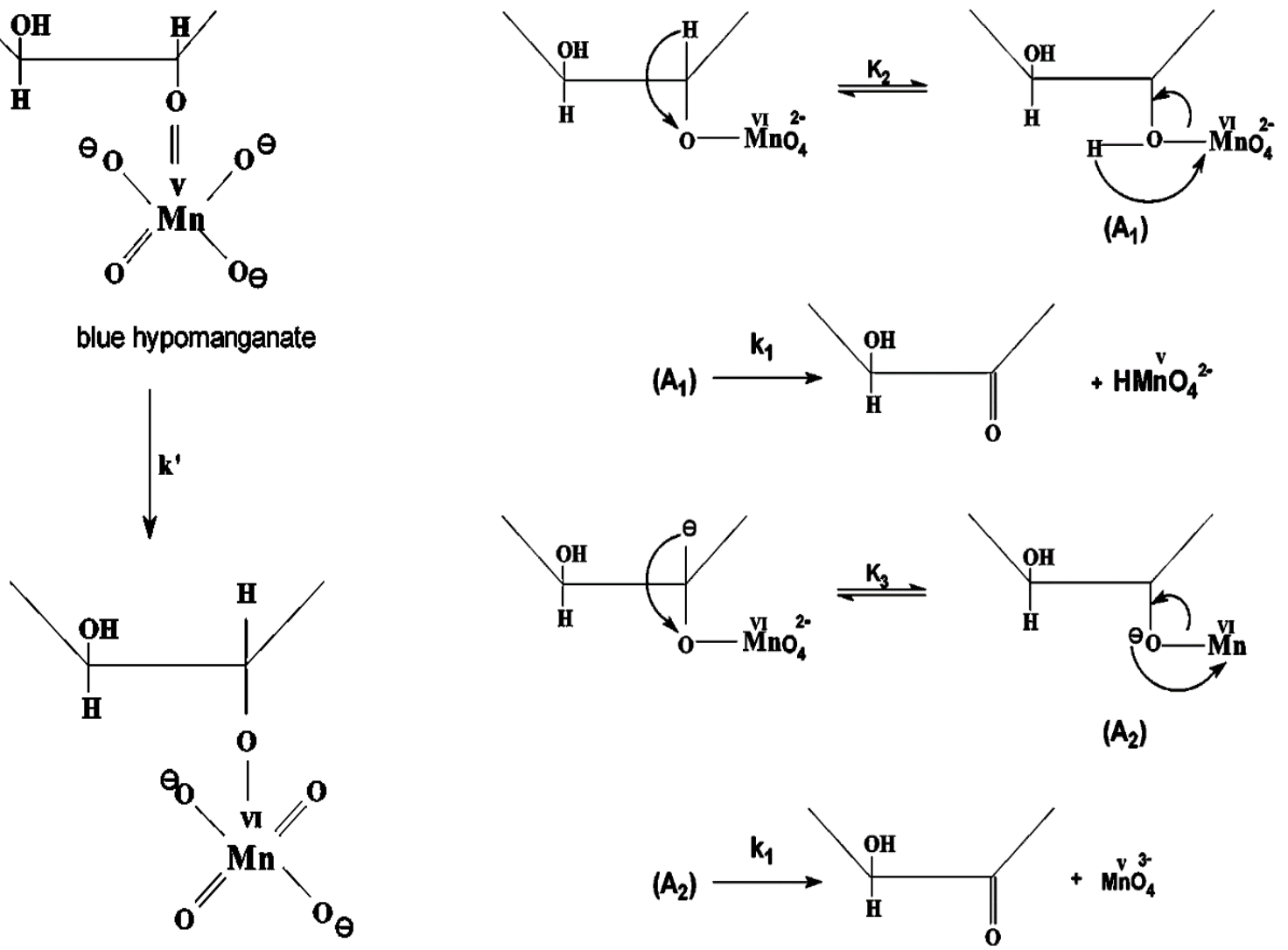

$\left(A_{1}\right)$

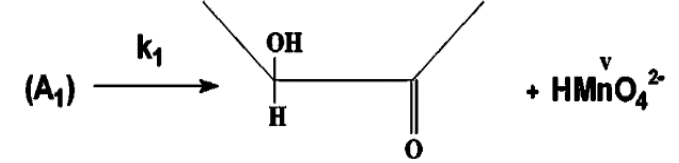<smiles>O=[W]1([O-])OCCO1</smiles>

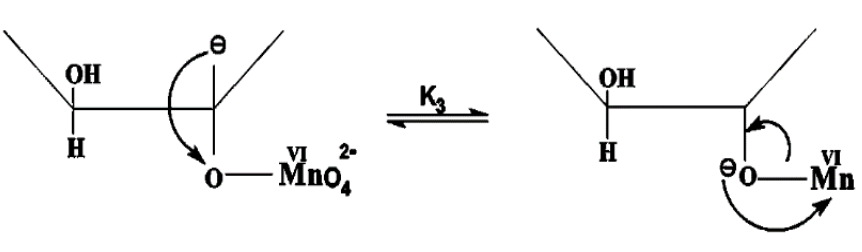

$\left(A_{2}\right)$

Figure 3. Mechanism of oxidation of methyl cellulose by permanganate ion in alkaline solutions 


\section{Chelation geometry with metal ions}

It was found that the oxidation product under our experimental conditions (diketo-methyl cellulose derivative) possesses a high tendency to chelate with many metal cations such as silver (I), di-, triand tetravalent metal ions, whereas the MC itself does not chelate with these metal ions. The characteristics and geometrical configuration of these complexes are in progress in our laboratory.

\section{Conclusion}

Diketomethyl cellulose can be used as a dietary fiber and a functional fiber when added to food. In addition, it found that the product has a high affinity for chelation with most of divalent and polyvalent metal ions forming stable coordination biopolymer complexes of methyl cellulose. The product is characterized by its non-toxicity, low cost and high performance. Diketomethyl cellulose can be used effectively for removal of poisonous heavy metal ions such as $\mathrm{Sn}^{2+}, \mathrm{Cd}^{2+}, \mathrm{Hg}^{2+}$ and $\mathrm{Pb}^{2+}, \mathrm{Ca}^{2+}$ along with other divalent and polyvalent metal ions which are contaminated in wastewater and environment.

\section{Conflicts of interest}

No.

\section{References}

1. McAllister JW, Lott JR, Schmidt PW, Sammler RL, Bates FS, et al. (2015) Linear and nonlinear rheological behavior of febrile methylcellulose hydrogels. ACS Macro Lett. 4: 538-542.

2. Gropper SS, Smith JI, Groff JL (2009) Advanced nutrition and human metabolism. $5^{\text {th }}$ Edn., Walsworth Cengage Learning, Chapter 4, USA, pp: 108.

3. Hassan RM (1993) Alginate polyelectrolyte ionotropic gels. XIV. Kinetics and mechanism of formation of intermediate complex during the oxidation of alginate polysaccharide by alkaline permanganate with a spectrophotometric evidence of manganate (VI) transient species. J Poly Sci 31: 51-59.

4. Khairou KS, Hassan RM (2000) Pectate polyelectrolyte ionotropic gels. I. Kinetics and mechanism of formation of manganate (VI)-pectate intermediate complex during oxidation of pectate polysaccharide by alkaline permanganate. Eur Poly $J$ 36: 20212030.

5. El-Khatib RM (2002)Spectrophotometric detection of methyl cellulose-manganate(VI) intermediate complex in the oxidation of methyl cellulose by alkaline permanganate. Carbohydr Poly 47: 377-385

6. Shaker AM, El-Khatib RM, Mahran HS (2007) Kinetics and mechanism of the decay of methyl cellulose-manganate(VI) polysaccharide transient species-novel spectrophotometric kinetic trace of methyl cellulose hypomangate $(\mathrm{V})$ gel intermediate polysaccharide. J Appl Poly Sci 106: 2668-2674.
7. Shaker AM (2001) Novel carboxymethyl cellulose ionotropic gels: II Kinetics of decomposition of the manganate(VI) intermediate-novel spectrophotometric tracer of the preformed short lived hypomanganate(V) coordination polymer sol. J Coll Interf Sci 244: 254-261.

8. Zaafarany IA, AlArifi A, Fawzy A, Ahmed GA, Ibrahim SA, et al. (2010) Further evidence for detection of short-lived transient hypomanganate (V) and manganate (VI) intermediates during oxidation of some sulfated polysaccharides by alkaline permanganate using conventional spectrophotometric techniques. Carbohyd Res 345: 1588-1593.

9. Hassan RM, Fawzy A, Alarifi A, Ahmed GA, Zaafarany IA, Takagi HD, et al. (2011) Base-catalyzed oxidation of some sulfated macromolecules: Kinetics and mechanism of formation of intermediate complexes of short-lived manganate(VI) and/ or hypomanganate $(\mathrm{V})$ during oxidation of iota- and lamba-carrageenan polysaccharides by alkaline permanganate. J Mol Cat 335: 38-45.

10. Zaafarany IA, Gobouri A, Hassan RM(2013) Oxidation of some sulfated carbohydrates: Kinetics and mechanism of oxidation of chondroitin-4-sulfate by alkaline permanganate with novel synthesis of coordination biopolymer precursor. J Mater Sci Res 2: 23 .

11. Gobouri AA, Zaafarany IA, Hassan RM (2013) Novel synthesis of diketo-acid chondroitin-4-sulfate as coordination biopolymer precursor through oxidation of chondroitin-4-sulfate by alkaline permanganate. Inter J Sci 2 : 1-9.

12. Hassan RM, Abd-Alla MA, El-Zohary MF (1993) Alginate polyelectrolyteIonotropic gels. VI. Novel synthesis of diketoalginate as bipolymer precursor. J Appl Poly Sci 47: 1649-1652.

13. Hassan RM (1993) Alginate polyelectrolyte ionotropic gels. XVIII. Oxidation of alginate polysaccharide by potassium permanganate in alkaline solutions. Kinetics of decomposition of the intermediate complex. J Poly Sci 31 : 1147-1151.

14. Hassan RM, Ahmed SM, Fawzy A, Abdel-Kader DA, Ikeda Y, et al. (2010) Acidcatalyzed oxidation of carboxymethyl cellulose polysaccharide by chromic acid in aqueous perchlorate solutions. A kinetic study. Cat Commun 11: 611-615.

15. Hassan RM, Mousa MA, El-Shatoury SA (1988) Kinetics of the oxidation of uranium (IV) by permanganate ion in aqueous perchlorate media. $J$ Chem Soc Dalton Trans 601-604.

16. Manhas MS, Mohammed F, Khan Z (2007) A kinetic study of oxidation of $\beta$-cyclodextrin by permanganate in aqueous media. Coll Surf 295:165-171.

17. Pretch E, Clerc T, Seibl J, Simon W (1983) Tables of spectral data for structure determination of organic compounds. Springer-Verlag, Berlin, Heidelberg, New York, Tokyo.

18. Hassan RM, Abd-Allah MA (1992) New coordination polymers.I. Novel synthesis of poly (vinyl alcohol) and characterization as chelating agent. J Mat Sci 2: 609-611.

19. Khairou KS, Hassan RM, Shaker MA (2002) Novel synthesis of diketocarboxymethyl cellulose as biopolymer precursors. J Appl Poly Sci 85: 1019-1023.

20. Hassan RM, Dahy A, Ibrahim S, Zaafarany IA, Fawzy A (2012) Oxidation of some macromolecules. Kinetics and mechanism of oxidation of methyl cellulose by permanganate ion in acid perchlorate solutions. Ind Engin Chem Res 51: 5424-5432.

Copyright: (2019 Hassan RM. This is an open-access article distributed under the terms of the Creative Commons Attribution License, which permits unrestricted use, distribution, and reproduction in any medium, provided the original author and source are credited. 